\title{
Jatrorrhizine suppresses the antimicrobial resistance of methicillin-resistant Staphylococcus aureus
}

\author{
HAIMING YU ${ }^{1}$, YUEFEI WANG ${ }^{2}$, XIAOQING WANG ${ }^{3}$, JUNJIE GUO $^{4}$, \\ HUI WANG ${ }^{5}, \mathrm{HAO}_{\mathrm{ZHANG}}{ }^{4}$ and FENGXIA DU ${ }^{4}$ \\ ${ }^{1}$ Department of Cerebral Surgery, The Second Affiliated Hospital of Qiqihar Medical University; \\ ${ }^{2}$ Department of Physiology, Physiology Section of Basic Medical Science College, Qiqihar Medical University, \\ Qiqihar, Heilongjiang 161000; ${ }^{3}$ Central Laboratory, General Hospital of Daqing Oil Field, \\ Daqing, Heilongjiang 163411; Departments of ${ }^{4}$ Pathogen Biology and ${ }^{5}$ Immunology, \\ Medical Technology College of Qiqihar Medical University, Qiqihar, Heilongjiang 161000, P.R. China
}

Received June 5, 2018; Accepted October 4, 2018

DOI: $10.3892 /$ etm.2019.8034

\begin{abstract}
Bacterial resistance to antimicrobial agents, including multidrug resistance, is an increasing problem in the treatment of infectious diseases. The development of resistance-modifying agents represents a potential strategy to alleviate the spread of bacterial resistance to antibiotics. A checkerboard microdilution assay was used to determine the synergy of jatrorrhizine and the antibiotic, norfloxacin (NFX). A bacterial ethidium bromide efflux assay, reverse transcription semi-quantitative polymerase chain reaction analysis and molecular docking study were performed. The three-dimensional structure of NorA multidrug efflux pump (NorA) was generated using a multiple threading approach. A murine thigh infection model was used to evaluate the in vivo synergistic effect. As a natural product, jatrorrhizine exhibited little antibacterial activity against methicillin-resistant Staphylococcus aureus (MRSA) SA1199B with a minimum inhibitory concentration (MIC) of $64 \mathrm{mg} / \mathrm{l}$. According to the investigations of the mechanism, jatrorrhizine significantly inhibited bacterial drug efflux and the expression of NorA in the mRNA level as it can bind to NorA by hydrogen-bonds, hydrophobic and electrostatic interactions. The in vivo synergistical bactericidal activity of jatrorrhizine and NFX against MRSA was confirmed in a murine thigh infection model. As a novel resistance-modifying agent, jatrorrhizine exhibited in vitro and in vivo synergistic activities against MRSA, and inhibited bacterial drug efflux. The effects were mediated by the suppression of NorA mRNA expression and/or interactions with NorA efflux pump. These data support the hypothesis that jatrorrhizine is a potential agent for therapeutic use in infections caused by MRSA.
\end{abstract}

Correspondence to: Miss Fengxia Du, Department of Pathogen Biology, Medical Technology College of Qiqihar Medical University, 333 Bukuibei Street, Qiqihar, Heilongjiang 161000, P.R. China E-mail: dufengxqmu@163.com

Key words: jatrorrhizine, methicillin-resistant Staphylococcus aureus, resistance-modifying agent, synergistic effect

\section{Introduction}

Antibiotics remain one of the most important discoveries in modern medicine and have proven to be powerful drugs in controlling infectious diseases. Although antibiotics have been successfully used for several decades, the widespread and unrestricted use of antibiotics have led to the development of antimicrobial resistance $(1,2)$. Bacterial resistance to antimicrobial agents, including multidrug resistance, is a major problem in the treatment of infectious diseases. Bacteria have the ability to rapidly acquire resistance genes through inter- and intra-species genetic transference, thus exacerbating the worldwide problem of resistant strains (3). The World Health Organization considers antibiotic resistance to be one of the greatest threats to the treatment of bacterial infectious diseases $(4,5)$. Approximately $50 \%$ of hospital acquired infections worldwide are caused by multidrug-resistant pathogens (6). The major mechanisms of antibiotic resistance include the inactivation of the antibiotic, target modification, alteration of drug access to the target through drug efflux and decreased uptake (2). Methicillin-resistant Staphylococcus aureus (MRSA) strains are some of the most tenacious antibiotic-resistant pathogens and contribute extensively to hospital-acquired infections (7). Bacterial multidrug efflux pumps are the major drivers of microbial resistance against several classes of antibiotics $(2,3)$. As the most well studied chromosomally-encoded efflux pump in pathogenic Gram-positive bacteria [such as Staphylococcus (S.) aureus], NorA multidrug efflux pump (NorA) is overexpressed in certain resistant mutants that demonstrate reduced susceptibility to quinolones, including norfloxacin (NFX) and ciprofloxacin $(3,8,9)$.

The discovery of novel antibiotics to combat resistant strains is therefore a major goal for the pharmaceutical industry $(4,10)$. However, since the 1960 s, the rate of development of novel antibiotic classes approved by the Food and Drug Administration has markedly reduced (2). A potential strategy to overcome the emergence of resistant strains is the discovery and development of novel drugs capable of partly or completely inhibiting bacterial resistance mechanisms, which have been 
termed resistance-modifying agents (RMAs) $(2,11)$. Plants provide a valuable source of novel chemical entities, which can contribute to the discovery of novel therapeutic agents. In fact, products derived from higher plants represent $\sim 25 \%$ of drugs in current clinical use $(2,12)$. Numerous plant-derived compounds act as bacterial RMAs against $S$. aureus $(2,13)$. For example, the indole alkaloid, reserpine, is a known NorA efflux pump inhibitor and exhibited a synergistic effect with ciprofloxacin (14).

Plants of the Mahonia genus, which is in the Berberidaceae family, have been widely used for a long time in Traditional Chinese Medicine as a treatment for tuberculosis, periodontitis, dysentery, icterus, pharyngolaryngitis, eczema and wounds (15). The majority of Mahonia species exert their effects by suppressing pain, inhibiting coughing and alleviating inflammation (15). The isolated compounds and crude extracts from Mahonia species exhibit a wide spectrum of in vitro and in vivo pharmacological effects, including antimicrobial, anti-inflammatory, hepatoprotective, antioxidant, antimutagenic and analgesic effects (15). Jatrorrhizine is one of the main protoberberine alkaloids widely distributed among Mahonia and Berberis species (15). In the current study, the in vitro and in vivo synergistic effects of jatrorrhizine and NFX against MRSA, and the underlying mechanisms were investigated.

\section{Materials and methods}

Materials. Optical density was recorded on a Multiskan ${ }^{\mathrm{TM}}$ FC Microplate Photometer (Thermo Fisher Scientific, Inc., Waltham, MA, USA) and fluorescence was measured on an Infinite ${ }^{\circledR}$ M1000 PRO Multimode reader (Tecan Group, Ltd., Mannedorf, Switzerland). Water was purified using a Milli-Q water purification system (EMD Millipore, Billerica, MA, USA).

Institute of Cancer Research (ICR) mice were obtained from Lingchang Biotechnology Co., Ltd. (Shanghai, China). All procedures were performed according to the Qiqihar Medical University guidelines, and approved by the Ethics Committee for Animal Care and the Use of Laboratory Animals at Qiqihar Medical University (Qiqihar, China). Specific pathogen-free ICR mice were bred in the animal facility of Qiqihar Medical University.

Antimicrobial assay. The MRSA strain, SA1199B, derived from a methicillin-susceptible $S$. aureus bloodstream isolate from a rabbit endocarditis model, previously described by Kaatz et al (16), which overexpresses the gene encoding NorA, was used in the present study (17). Minimum inhibitory concentrations (MICs) were determined following the guidelines of Clinical Laboratory Standards Institute (18). Mueller-Hinton broth (MHB; Oxoid; Thermo Fisher Scientific, Inc.), containing $20 \mathrm{mg} / 1 \mathrm{Ca}^{2+}$ and $10 \mathrm{mg} / 1 \mathrm{Mg}^{2+}$, was used in the assay. All bacterial suspensions were adjusted to $5 \times 10^{5} \mathrm{Cfu} / \mathrm{ml}$ for the bioassay, cells were seeded at a density of $5 \times 10^{4}$ cells/well in 96-well plates. Ofloxacine (Sigma-Aldrich; Merck KGaA, Darmstadt, Germany) served as the positive control and $2 \%$ DMSO in MHB as the negative control. Controls and treatments were assessed in duplicate. Following the incubation at $37^{\circ} \mathrm{C}$ for $18-24 \mathrm{~h}, 20 \mu \mathrm{l}$ MTT solution $(5 \mathrm{mg} / \mathrm{ml}$; Biosharp,
Solon, OH, USA) was added into each well and incubated at $37^{\circ} \mathrm{C}$ for $2-4 \mathrm{~h}$. Concentrations that completely inhibited the visible bacterial growth (from light yellow to deep purple) were recorded as MIC values against the SA1199B strain. The optical density in each well was measured at $570 \mathrm{~nm}$. The $50 \%$ effective concentrations $\left(\mathrm{EC}_{50} \mathrm{~s}\right)$ were calculated based on the percentage of bacteria growth inhibition following the treatment of the bacteria with different concentrations of compounds.

Synergy assays. Using the strain SA1199B, a checkerboard microdilution assay was employed to examine for the presence of a synergistic interaction of antimicrobes (19). Jatrorrhizine or reserpine (both Dalian Meilun Biotech Co., Ltd., Dalian, China) in a concentration range of 2-128 mg/l $(2,4,8,16,32$, 64 and $128 \mathrm{mg} / \mathrm{l}$ ) was tested in combination with NFX (Dalian Meilun Biotech Co., Ltd.) against the tested S. aureus strain; the concentration range of NFX was $0.5-256 \mathrm{mg} / 1(0.5,1,2,4$, $8,16,32,64,128$ and $256 \mathrm{mg} / \mathrm{l})$. Cells were seeded at a density of $5 \times 10^{4}$ cells/well in 96-well plates. All treatments were tested in duplicate wells. Following the incubation at $37^{\circ} \mathrm{C}$ for $18-24 \mathrm{~h}$, $20 \mu 1$ MTT solution ( $5 \mathrm{mg} / \mathrm{ml}$; Biosharp) was added into each well and incubated at $37^{\circ} \mathrm{C}$ for $2-4 \mathrm{~h}$. MIC values were used to evaluate the effects of the combination by calculating the fractional inhibitory concentration index (FICI) according to the following formula:

$$
\begin{gathered}
\text { FICI }=\frac{\text { MIC (antibiotic combined with compound) }}{\text { MIC (antibiotic alone) }}+ \\
\frac{\text { MIC (compound combined with antibiotic) }}{\text { MIC (compound alone) }}
\end{gathered}
$$

'Synergy' was confirmed when the FICI was $\leq 0.5$. When the FICI ranged from 0.5-4.0 the effect was regarded as 'indifferent', whereas an 'antagonistic' effect was confirmed when the FICI was $>4.0$.

Growth kinetics. The growth kinetics of SA1199B cells were assessed to elucidate the effect of NFX in the presence of jatrorrhizine in MHB, and evaluated using a time-growth curve method, as described previously $(14,20)$. A bacterial suspension in its logarithmic phase $\left(1 \times 10^{6} \mathrm{Cfu} / \mathrm{ml}\right)$ was used as the inoculum. The growth kinetics were analysed following the treatment of NFX at $16 \mathrm{mg} / \mathrm{ml}(1 / 4 \mathrm{MIC})$ alone and in combination with jatrorrhizine at $16 \mathrm{mg} / \mathrm{ml}(1 / 4 \mathrm{MIC})$. The $\mathrm{cfu} / \mathrm{ml}$ was determined by a serial dilution method (21) on Mueller-Hinton agar (MHA; Yeasen Biotech, Shanghai, China) plates at $37^{\circ} \mathrm{C}$ for $2,4,6,8,10,12$ and $24 \mathrm{~h}$.

Ethidium bromide (EtBr) efflux assay. Jatrorrhizine was subjected for a bacterial drug efflux assay as described previously (22). The efflux activity of strain SA1199B was determined by measuring the accumulation of the fluorescent dye $\operatorname{EtBr}(25 \mu \mathrm{M}$; Aladdin Shanghai Biochemical Technology Co., Ltd., Shanghai, China) in the absence or presence of known efflux inhibitor carbonyl cyanide 3-chlorophenylhydrazone (CCCP; $100 \mu \mathrm{M}$; J\&K Chemical, Ltd., Beijing, China) and in the absence or presence of jatrorrhizine $(16 \mathrm{mg} / \mathrm{l})$. Cells were seeded at a density of $5 \times 10^{4}$ cells/well in 96 -well plates. With an excitation wavelength of $530 \mathrm{~nm}$ and emission wavelength of $600 \mathrm{~nm}$, the fluorescence of the suspension was monitored 
Table I. Primers used for nor A and 16s rRNA.

\begin{tabular}{llll}
\hline Gene & Primer & \multicolumn{1}{c}{ Sequence $\left(5^{\prime}-3^{\prime}\right)$} & Size $(\mathrm{bp})$ \\
\hline norA & Sense & GTTGCTGCTTTCGCCTTATCTC & 200 \\
norA & Antisense & GGCATAACCATACCAGCACTCA & 195 \\
16 s rRNA & Sense & GCTCGTGTCGTGAGATGTTGG & \\
16 s rRNA & Antisense & TTTCGCTGCCCTTTGTATTGT & \\
\hline
\end{tabular}

rRNA, ribosomal RNA.

every $5 \mathrm{~min}$ for $1 \mathrm{~h}$ (slit width, $5 \mathrm{~nm}$ ). The assay was performed in triplicate.

Total RNA extraction and semi-quantitative reverse transcription-polymerase chain reaction ( $R T-P C R)$. Total RNA was isolated from the bacteria using the TRIzol reagent (Thermo Fisher Scientific, Inc.) following the manufacturer's protocol. The reverse transcription step was conducted using the RevertAid ${ }^{\mathrm{TM}}$ First Strand cDNA Synthesis kit (Thermo Fisher Scientific, Inc.) to synthesise cDNA following the manufacturer's protocol. The semi-quantitative PCR analysis was performed using the 2X Taq PCR MasterMix (PC1120; Beijing Solarbio Science \& Technology Co., Ltd., Beijing, China) and with an ABI 7300 real-time fluorescent quantitative PCR system (Applied Biosystems; Thermo Fisher Scientific, Inc.). The PCR thermocycling parameters were as follows: $95^{\circ} \mathrm{C}$ for $1 \mathrm{~min}$ followed by 40 cycles of $95^{\circ} \mathrm{C}$ for $15 \mathrm{sec}, 58^{\circ} \mathrm{C}$ for $25 \mathrm{sec}$ and $72^{\circ} \mathrm{C}$ for $20 \mathrm{sec}$, and a final extension step of $72^{\circ} \mathrm{C}$ for $5 \mathrm{~min}$. The relative gene expression was calculated by the $2^{-\Delta \Delta \mathrm{Cq}}$ method (23). Each sample was assessed in duplicate and all the samples were analysed in parallel for the expression of the housekeeping gene 16s rRNA, which was used as an endogenous control for normalisation of the expression level of target genes. The fold induction was determined from the mean replicate values. At the end of the RT-PCR assay, equal amounts of the final amplified product of each sample was loaded in $2 \%$ agarose gel and subjected to electrophoresis and visualized using ethidium bromide (1610433; Bio-Rad Laboratories, Inc., Hercules, CA, USA) staining. The densitometry analysis was performed with ImageJ version 1.48 software (National Institutes of Health, Bethesda, MD, USA). The primer sequences for the analysis of NorA and 16s rRNA genes are described in Table I.

Molecular modeling. The three-dimensional structure of jatrorrhizine was built using ChemDraw Ultra 14.0 and ChemBio3D ${ }^{\circledR}$ Ultra 14.0 (CambridgeSoft Corp., Waltham, MA, USA). The structure was constructed using the Prepare Ligands modules in Discovery Studio software (version 2016; Biovia Corp., San Diego, CA, USA). The amino acid sequence of NorA was investigated in the National Center for Biotechnology Information database (GI: 153055; Accession: AAA26658.1). The glycerol-3-phosphate transporter from Escherichia coli (Protein Data Bank ID: 1PW4) was selected from the Protein Data Bank database and used as template for NorA in the docking studies (14). The NorA homology model for molecular docking was created on the I-TASSER server (https://zhanglab.ccmb.med.umich. edu/I-TASSER/), which is one of the computational tools for automated protein 3D structure prediction (24-26), then refined by Fragment-Guided Molecular Dynamics simulation (27). The optimized model was further evaluated using server-based structural verification from the UCLA-DOE Institute for Genomics and Proteomics server. The probable binding site of the modeled structure was identified using the Define and Edit Binding Site Module, and then applied to the Flexible Docking Module for flexible docking studies with Chemistry at HARvard Macromolecular Mechanics force fields in Discovery Studio software.

Murine thigh infection model. The intramuscular infection model was based on methods described previously (28) using 4-6 week-old male ICR mice (18-20 g). A total of 70 mice were provided with free access to food and water, and housed at room temperature $\left(25^{\circ} \mathrm{C}\right)$ with a 12 -h light/dark cycle and humidity of $65-70 \%$. They were rendered neutropenic by intraperitoneally (i.p.) injecting them with 150 and $100 \mathrm{mg} / \mathrm{kg}$ cyclophosphamide at 4 days and 1 day prior to inoculation, respectively. The colonies of MRSA SA1199B grown on MHA plates were suspended in MHB and then incubated at $37^{\circ} \mathrm{C}$ overnight. The animals were injected intramuscularly with $1 \times 10^{5}$ CFU MRSA SA1199B and antimicrobial treatment was started $1 \mathrm{~h}$ following bacterial challenge. The mice were divided into five groups treated ( $n=10 /$ group) with a drug-free solution [0.5\% w/v sodium carboxymethyl-cellulose, $0.5 \mathrm{ml} / 20 \mathrm{~g}$; oral administration (p.o.)], jatrorrhizine (50 mg/kg,i.p.), NFX [100 mg/kg, p.o.], a combination of jatrorrhizine $(10,25$ or $50 \mathrm{mg} / \mathrm{kg}$, i.p.) and NFX (100 mg/kg, p.o.) or ofloxacine $(50 \mathrm{mg} / \mathrm{kg}$, p.o.; Dalian Meilun Biotech Co., Ltd.). The mice that received the drug-free solution were deemed the control group. A total of $24 \mathrm{~h}$ after infection, the mice were euthanized, the muscle was removed and then homogenized in $1 \mathrm{ml}$ PBS to recover the bacteria. In order to count the viable MRSA colonies, samples were serially diluted and plated onto MHA plates, and incubated at $37^{\circ} \mathrm{C}$ for $24 \mathrm{~h}$. The bacterial colonies $(\sim 1 \mathrm{~mm})$ on agar plates counted visually were used for determing viable bacteria in samples. Bacterial quantities are displayed as $\ln (\mathrm{Cfu} / \mathrm{ml})$ in all treatment groups.

Statistical analysis. The data are presented as mean \pm standard deviation of two or three separate experiments. Significant differences were established by one-way analysis of variance and post hoc Tukey's test using GraphPad Prism (version 5; 
Table II. MIC and FICI of agents against Staphylococcus aureus SA1199B.

\begin{tabular}{|c|c|c|c|c|c|}
\hline \multirow[b]{2}{*}{ Agent } & \multicolumn{2}{|c|}{ MIC (mg/l) } & \multirow[b]{2}{*}{$\mathrm{EC}_{50}(\mathrm{mg} / \mathrm{l})$} & \multirow[b]{2}{*}{ FICI } & \multirow[b]{2}{*}{$\begin{array}{c}\text { FICI in combination } \\
\text { with jatrorrhizine }\end{array}$} \\
\hline & Alone & $\begin{array}{c}\text { Combined with } \\
16 \mathrm{mg} / \mathrm{ljatrorrhizine}\end{array}$ & & & \\
\hline Jatrorrhizine & 64 & - & 27.1 & 0.250 & - \\
\hline Norfloxacin & 64 & 8 & 21.6 & 0.125 & 0.375 \\
\hline Reserpine & 128 & 16 & - & 0.125 & 0.250 \\
\hline Ofloxacine & 1 & - & - & - & - \\
\hline
\end{tabular}

MIC, minimum inhibitory concentration; FICI, fractional inhibition concentration index.

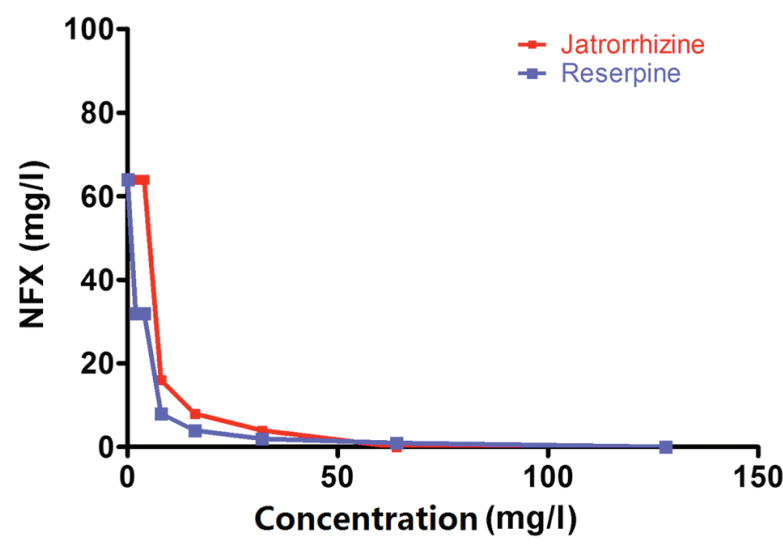

Figure 1. Jatrorrhizine or reserpine exhibited synergistic effect with NFX against MRSA. The concentrations of jatrorrhizine and reserpine ranged from 2-64 mg/l and the concentration of NFX ranged from 0.5-64 mg/1. NFX, norfloxacin.

GraphPad Software, Inc., La Jolla, CA, USA). P<0.05 indicated that the difference between groups was statistically significant.

\section{Results}

Jatrorrhizine or NFX alone exhibits low antimicrobial activity. Jatrorrhizine was subjected to an antibacterial assay against MRSA strain SA1199B. The MICs of jatrorrhizine and NFX were measured as $64 \mathrm{mg} / \mathrm{l}$; the two agents exhibited low antibacterial activity against MRSA SA1199B (Table II). As the positive control, the antibiotic ofloxacine substantially inhibited the growth of MRSA SA1199B with an MIC of $1 \mathrm{mg} / \mathrm{l} .2 \%$ DMSO (negative control) showed no inhibition on bacterial growth. The $\mathrm{EC}_{50} \mathrm{~s}$ of jatrorrhizine and NFX were determined to be 27.1 and $21.6 \mathrm{mg} / 1$, respectively. The $\mathrm{EC}_{50}$ values were high, supporting the antimicrobial activities of jatrorrhizine and NFX.

Jatrorrhizine exhibits a synergistic effect with NFX against $M R S A$. Jatrorrhizine alone exhibited little antibacterial activity with an MIC of $64 \mathrm{mg} / \mathrm{l}$ (Table II and Fig. 1). The strain SA1199B was resistant to the antibiotic, NFX (MIC, $64 \mathrm{mg} / \mathrm{l}$; Table II). When the bacteria were incubated with a combination of jatrorrhizine and NFX, the MIC of NFX was

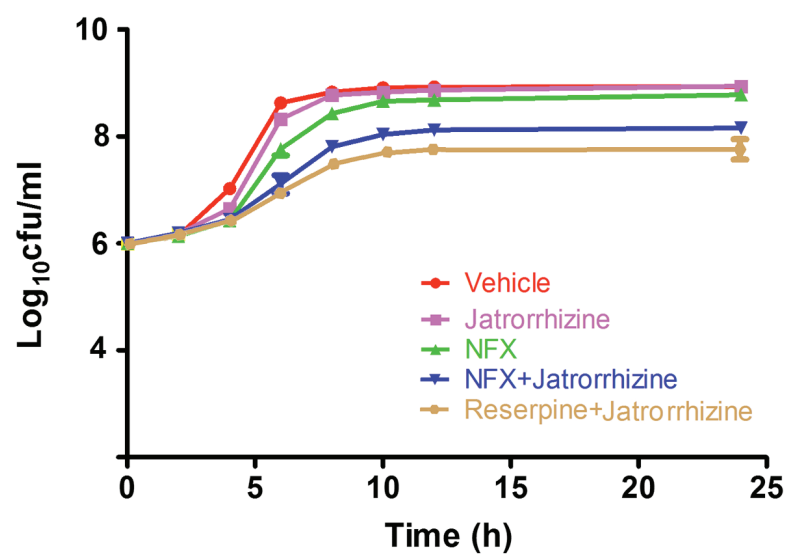

Figure 2. A combination of NFX and jatrorrhizine reduced the growth of methicillin-resistant Staphylococcus aureus SA1199B over $24 \mathrm{~h}$. The MIC for each drug was $64 \mathrm{mg} / 1$, therefore the SA1199B strain was treated with $16 \mathrm{mg} / 1$ (1/4 MIC) of each drug or vehicle. Data are presented as mean \pm standard deviation of three independent experiments. NFX, norfloxacin; MIC, minimum inhibitory concentration.

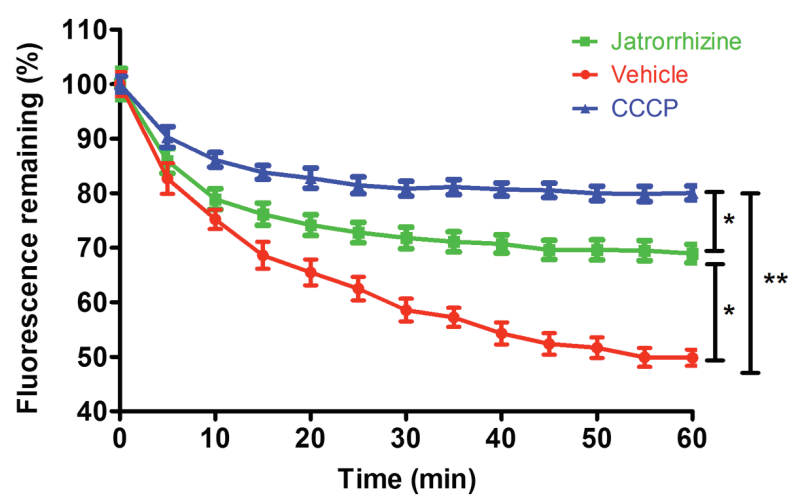

Figure 3. Jatrorrhizine inhibits bacterial drug efflux. Methicillin-resistant Staphylococcus aureus SA1199B was treated with $16 \mathrm{mg} / 1$ jatrorrhizine, $100 \mu \mathrm{M}$ CCCP or vehicle. Data are presented as mean \pm standard deviation of three independent experiments. ${ }^{*} \mathrm{P}<0.05,{ }^{* *} \mathrm{P}<0.01$. CCCP, carbonyl cyanide 3-chlorophenylhydrazone.

markedly reduced compared with NFX alone. The synergistic effect between jatrorrhizine and NFX against the strain SA1199B was confirmed with an FICI of 0.375. However, reserpine demonstrated a better synergistic effect with an FICI of 0.250 . 
A

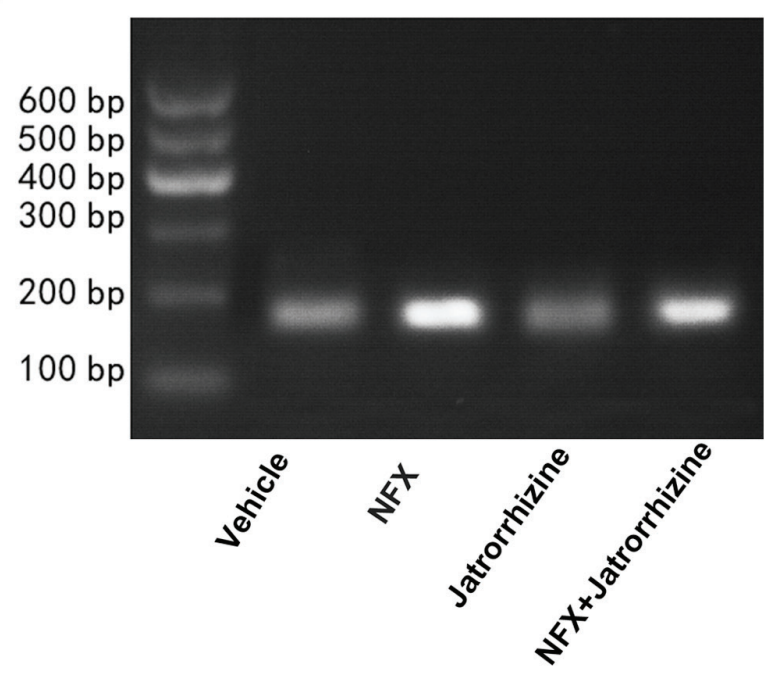

B

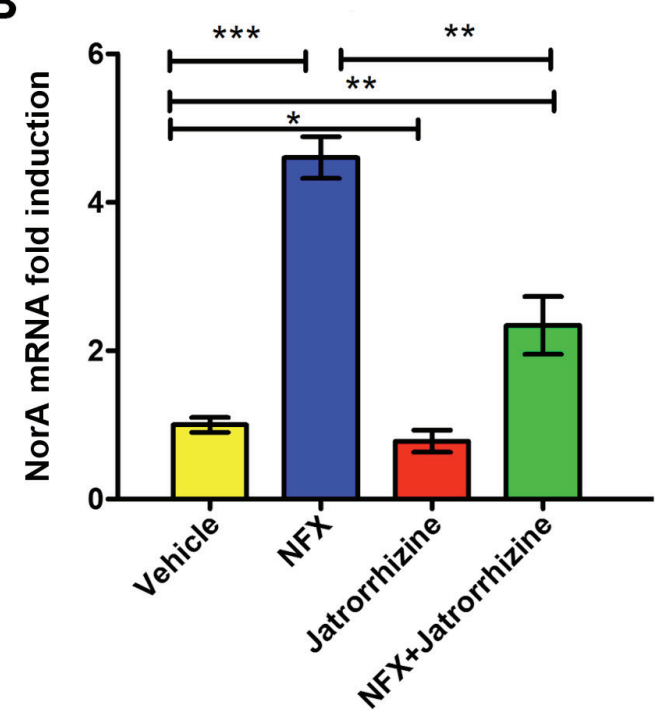

Figure 4. Influence of jatrorrhizine on the expession of NorA at mRNA level. The MIC for each drug was $64 \mathrm{mg} / 1$, therefore the SA1199B strain was treated with $16 \mathrm{mg} / 1$ (1/4 MIC) of each drug or vehicle. The (A) qualitative and (B) semi-quantitative analysis of NorA mRNA expression in methicillin-resistant Staphylococcus aureus SA1199B. Data are presented as mean \pm standard deviation of five independent experiments. ${ }^{*} \mathrm{P}<0.05,{ }^{* * *} \mathrm{P}<0.01,{ }^{* * *} \mathrm{P}<0.001$. $\mathrm{NFX}$, norfloxacin; NorA, NorA multidrug efflux pump; MIC, minimum inhibitory concentration.

MRSA proliferation is inhibited by jatrorrhizine with NFX. To further confirm the synergistic effect between jatrorrhizine and NFX, time-growth experiments of the SA1199B strain without treatment or treated with NFX, jatrorrhizine, reserpine or a combination of two (Fig. 2). Jatrorrhizine did not significantly inhibit the SA1199B strain at $16 \mathrm{mg} / 1$ (1/4 MIC), as shown in Fig. 2. The SA1199B strain did not markedly increase with the first $4 \mathrm{~h}$ of $1 / 4$ MIC NFX treatment; however, proliferation markedly increased from 6-10 h. Compared with NFX alone, the SA1199B strain treated with NFX (1/4 MIC) combined with jatrorrhizine (1/4 MIC) grew at a slower rate. Jatrorrhizine markedly enhanced the antibacterial activity of NFX against MRSA, suggesting the synergistic effect between NFX and jatrorrhizine, even the effect was weaker compared with reserpine in combination with jatrorrhizine.

Jatrorrhizine inhibited bacterial EtBr efflux. Measuring the accumulation of EtBr demonstrated that jatrorrhizine inhibited the efflux pump of the SA1199B strain (Fig. 3). Compared with the vehicle-treated bacteria, in which fluorescence was quickly reduced to $<50 \%$, the reduction in fluorescence was significantly slower in the jatrorrhizine-treated bacteria $(\mathrm{P}<0.05)$ as the fluorescence level plateaued at $\sim 70 \%$. The positive control CCCP significantly $(\mathrm{P}<0.01)$ inhibited the efflux of EtBr cells with the fluorescence retention of $\sim 80 \%$. Therefore, jatrorrhizine inhibited bacterial drug efflux in the SA1199B strain, although its inhibition was significantly weaker compared with the known efflux inhibitor, CCCP $(\mathrm{P}<0.05)$. Drug efflux is one of the important bacterial resistance mechanisms. Thus, jatrorrhizine may be a resistance-modifying agent against bacteria resistance.

Inhibitory effect of jatrorrhizine on induction of NorA at the transcriptional level. The expression of the NorA mRNA was investigated (Fig. 4A). The expression of the NorA mRNA in vehicle-treated bacteria was set as a 1-fold induction. Jatrorrhizine (16 mg/1, 1/4 MIC) significantly inhibited the expression of NorA compared with the vehicle $(\mathrm{P}<0.05$; Fig. 4B). Compared with the vehicle, the expression of NorA was significantly increased in the SA1199B strain following the incubation with NFX $(16 \mathrm{mg} / 1,1 / 4 \mathrm{MIC}$; $\mathrm{P}<0.001)$ and a combination of NFX and jatrorrhizine $(\mathrm{P}<0.01)$. However, the level of NorA mRNA expression in bacteria treated with a combination of NFX and jatrorrhizine was significantly higher compared with that of NFX-treated bacteria $(\mathrm{P}<0.01)$. Therefore, jatrorrhizine significantly decreased the antibiotic-induced expression of NorA at the mRNA level, thus assisting in the treatment of MRSA.

NorA-jatrotthizine complex formed by interactions. According to docking study, the NorA-jatrotthizine complex was formed by NorA-jatrotthizine interactions cluding hydrophobicity, as shown in Fig. 5A. The functional groups in NorA involved in the jatrorrhizine binding site were formed by Met263, Asn315, Phe259, Ala312, Tyr316, Leu269, Thr270, Phe271, Arg380, Lys377, Glu268, Asn319 and Lys384 (Fig. 5B). It was observed that Ala312 and Thr27 are associated with key interactions and hence serve an important role in ligand binding. A hydrophobic cleft formed by Met263, Asn315, Phe259, Tyr316, Leu269, Phe271, Lys377 and Lys384 provided extra stability to the complex. Also, the electrostatic interaction between the benzene ring and polar groups of the amino acid residues on Glu268 and Arg380 contributed extra stability to the NorA-jatrotthizine complex. The docking results suggest that jatrotthizine binds to NorA with hydrogen bonds, and hydrophobic and electrostatic interactions, which may be associated with its inhibitory efflux pump activity.

In vivo synergistic efficacy of jatrorrhizine and NFX in a neutropenic murine thigh infection model. To validate the in vivo synergistic bactericidal activity of jatrorrhizine and 
A

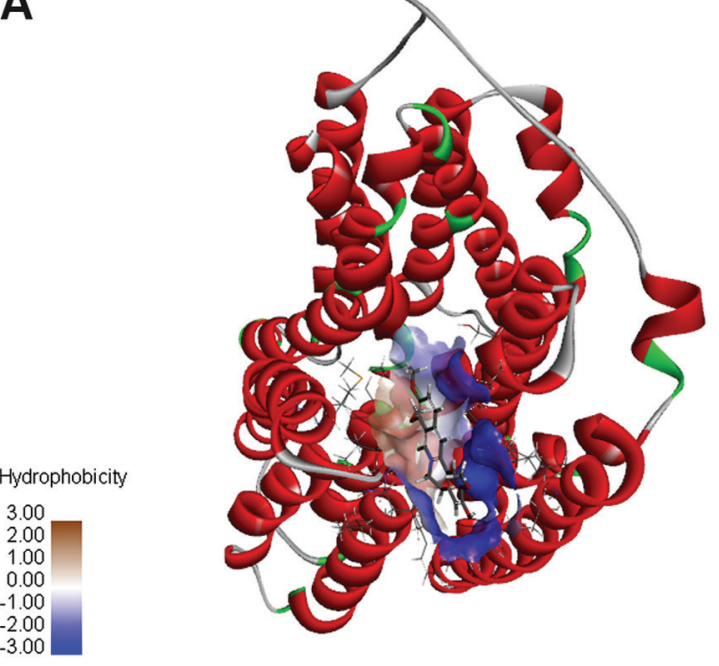

B

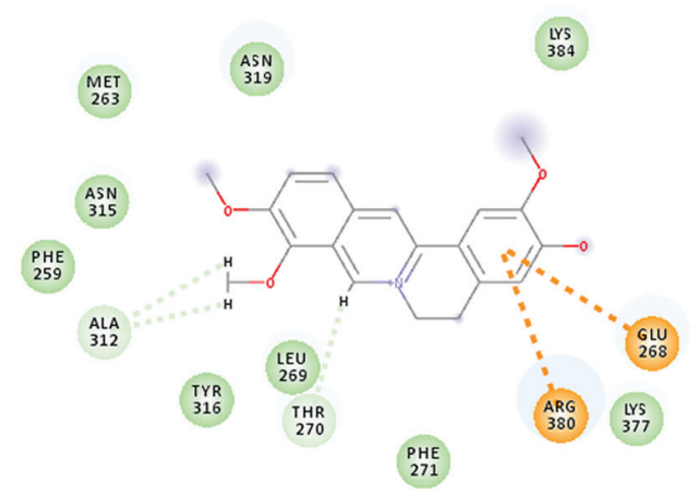

Interactions

van der waals

Carbon hydrogen bond
Pi-Cation

Pi-Anion

Figure 5. Jatrorrhizine forms a stable complex with NorA. (A) The hydrophobic interaction between jatrorrhizine and the hydrophobic cleft of NorA. (B) Interactions are demonstrated between jatrorrhizine and amino acid residues (hydrogen bonds) or polar groups (electrostatic interaction). Interactions: Hydrophobic interaction (green), hydrogen bond (light green) and electrostatic interaction (orange). NorA, NorA multidrug efflux pump.

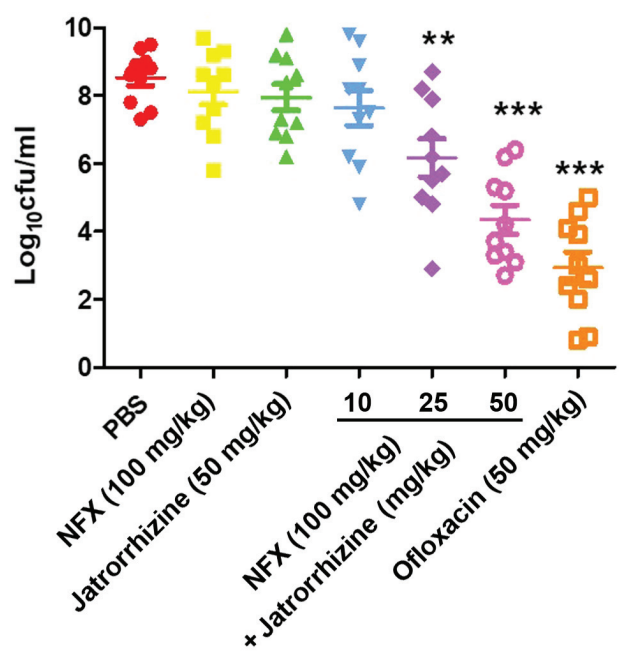

Figure 6. A combination of NFX and jatrorrhizine reduced the growth of MRSA SA1199B after $24 \mathrm{~h}$ in neutropenic mice models. A total of 10 mice were intramuscularly infected with MRSA strain SA1199B. After $1 \mathrm{~h}$ the animals were treated with PBS, jatrorrhizine, NFX, combination of jatrorrhizine and NFX or oflaxacin. Thigh samples were collected after $24 \mathrm{~h} .{ }^{* *} \mathrm{P}<0.01$ ${ }^{* * * *} \mathrm{P}<0.001$ vs. PBS. MRSA, methicillin-resistant Staphylococcus aureus; NFX, norfloxacin.

NFX against the MRSA strain, SA1199B, a mouse model of thigh infection was used. The results revealed that ofloxacine $(50 \mathrm{mg} / \mathrm{kg})$, a positive control, significantly decreased the bacterial burden after $24 \mathrm{~h}$ compared with that of the PBS-treated animals (Fig. 6). No significant difference in the bacteria count was identified between the groups treated with jatrorrhizine $(50 \mathrm{mg} / \mathrm{kg})$, NFX $(100 \mathrm{mg} / \mathrm{kg})$, a combination of jatrorrhizine NFX (10 and $100 \mathrm{mg} / \mathrm{kg}$, respectively) or PBS. However, the bacterial count in the groups treated with a combination of jatrorrhizine $(25$ or $50 \mathrm{mg} / \mathrm{kg}$ ) and NFX $(100 \mathrm{mg} / \mathrm{kg})$ significantly decreased in what appears to be a dose-dependent manner $(\mathrm{P}<0.01$ and $\mathrm{P}<0.001$, respectively, suggesting that there is an in vivo synergistic effect.

\section{Discussion}

Natural products, particularly those from plants, are an important source for drug discovery (29). The efficiency of strategy that combines antimicrobials with an agent capable of the inhibition of resistance mechanisms has been developed with the successful clinical use of $\beta$-lactams in combination with $\beta$-lactamase inhibitors, such as clavulanic acid in combination with amoxicillin (2). Efflux mechanisms are widespread in bacteria and serve a role in susceptibility and resistance to antibiotics; developing efflux-pump inhibitors to be used in combination with existing antimicrobials is appealing and may facilitate the recycling of existing antibiotics (3).

The MRSA strain SA1199B overexpresses the gene encoding the NorA multidrug resistant efflux pump, which reduces susceptibility of the bacteria to quinolones, such as NFX (2). The development of RMAs provides a potential strategy to alleviate the spread of bacterial antibiotic resistance (30). Several protoberberine alkaloids including berberine, jatrorrhizine and palmatine were previously measured against MRSA strains; only jatrorrhizine exhibited a synergistic effect with NFX. In the present study, the antibacterial activity of jatrorrhizine against MRSA SA1199B was revealed to be an MIC of $64 \mathrm{mg} / \mathrm{l}$, suggesting it is a weak antibacterial agent. However, the synergy assay revealed that jatrorrhizine and NFX against MRSA SA1199B had an FICI of 0.375. With an FICI <0.5, jatrorrhizine reduced the MIC of NFX, which resulted in an 8-fold decrease in the bacterial count of MRSA SA1199B. In order to confirm the synergistic effect, the growth kinetics were measured in $24 \mathrm{~h}$, which demonstrated that jatrorrhizine synergistically inhibited the growth of MRSA with NFX. As one of the most important antibacterial resistance mechanisms, bacterial drug efflux prevents antimicrobials accessing the targets in bacteria. In the current study, a bacterial drug efflux assay demonstrated that jatrorrhizine significantly inhibited the EtBr efflux of MRSA SA1199B. 
NFX has been demonstrated to inhibit bacterial activity by blocking nucleic acids synthesis (31). Incubating resistant bacteria with substrates of the NorA efflux pump, such as NFX, can induce norA overexpression at the mRNA and protein levels (32). According to the semi quantitative RT-PCR analysis, the overexpression of NorA induced by NFX was suppressed by jatrorrhizine at the mRNA level. This result suggests that jatrorrhizine exhibited a synergistic effect with NFX against MRSA through the suppression of NorA mRNA expression.

Molecular docking is a widely used technology, which has served an important role in drug design (33). It is one of the fundamental tools to elucidate the association between the structure of a ligand and its biological activities. To further investigate the mechanism of the synergistic antibacterial activity of jatrorrhizine and NFX, the three-dimensional structure of NorA was generated and a molecular docking study of the interactions between NorA and jatrorrhizine was performed. It was revealed that jatrorrhizine extended into the hydrophobic cleft formed by Met263, Asn315, Phe259, Tyr316, Leu269, Phe271, Lys377 and Lys384 in the binding site. H-bonds and electrostatic interactions between jatrorrhizine and amino acid residues were formed in the binding site, contributing to a stable NorA-jatrorrhizine complex. NorA in bacteria confers resistance to NFX by effluxing NFX from cell. The interactions between NorA and jatrorrhizine altered the function of the NorA efflux pump, inhibiting NFX efflux. As a result, jatrorrhizine may be a potential NorA efflux pump inhibitor.

NorA overexpression reduces the susceptibility of MRSA to quinolones and the use of RMAs to inhibit NorA mRNA expression can increase the susceptibility quinolones (2). Jatrorrhizine significantly increased the antimicrobial effect of NFX against MRSA SA1199B infection in mice, suggesting that there is an in vivo synergistic effect between jatrorrhizine and NFX.

In conclusion, jatrorrhizine is a novel RMA against MRSA. To the best of our knowledge, the current study is the first to reveal that jatrorrhizine exhibits in vitro and in vivo synergistic effects with NFX against MRSA. The effects are mediated by the suppression of NorA mRNA expression and bacterial drug efflux or the inhibition of bacterial drug efflux through the binding of NFX and jatrorrhizine to the NorA efflux pump. These data support the hypothesis that jatrorrhizine is a potential agent for therapeutic use in infections caused by MRSA.

\section{Acknowledgements}

Not applicable.

\section{Funding}

The current study was supported by the fund of scientific research project of Heilongjiang Provincial Education Department (grant no. 2016-KYYWF-0839).

\section{Availability of data and materials}

The datasets used and/or analyzed during the current study are available from the corresponding author on reasonable request.

\section{Authors' contributions}

FD provided the conception and design of the study. HY analyzed experimental data. YW, XW, JG, HW and HZ performed the experiments. HY and FD were the major contributors in writing the manuscript. All authors read and approved the final manuscript.

\section{Ethics approval and consent to participate}

The present study was approved by the Ethics Committee of Medical Technology College of Qiqihar Medical University (Qiqihar, China).

\section{Patient consent for publication}

Not applicable.

\section{Competing interests}

The authors declare that they have no competing interests.

\section{References}

1. Russell AD: Biocide use and antibiotic resistance: The relevance of laboratory findings to clinical and environmental situations. Lancet Infect Dis 3: 794-803, 2003.

2. Abreu AC, McBain AJ and Simoes M: Plants as sources of new antimicrobials and resistance-modifying agents. Nat Prod Rep 29: 1007-1021, 2012.

3. Hooper DC: Efflux pumps and nosocomial antibiotic resistance: A primer for hospital epidemiologists. Clin Infect Dis 40: 1811-1817, 2005

4. Oluwatuyi M, Kaatz GW and Gibbons S: Antibacterial and resistance modifying activity of Rosmarinus officinalis. Phytochemistry 65: 3249-3254, 2004.

5. Wright GD: Bacterial resistance to antibiotics: Enzymatic degradation and modification. Adv Drug Deliv Rev 57: 1451-1470, 2005.

6. Hoffman SB: Mechanisms of antibiotic resistance. Compendium on Continuing Education for the Practising Veterinarian-North American Edition 23: 464-472, 2001.

7. Gould IM, Reilly J, Bunyan D and Walker A: Costs of healthcare-associated methicillin-resistant Staphylococcus aureus and its control. Clin Microbiol Infect 16: 1721-1728, 2010.

8. Neyfakh AA, Borsch CM and Kaatz GW: Fluoroquinolone resistance protein NorA of Staphylococcus aureus is a multidrug efflux transporter. Antimicrob Agents Chemother 37: 128-129, 1993.

9. Truong-Bolduc QC, Zhang X and Hooper DC: Characterization of NorR protein, a multifunctional regulator of norA expression in Staphylococcus aureus. J Bacteriol 185: 3127-3138, 2003.

10. Alekshun MN and Levy SB: Molecular mechanisms of antibacterial multidrug resistance. Cell 128: 1037-1050, 2007.

11. Mallea M, Mahamoud A, Chevalier J, Alibert-Franco S, Brouant $\mathrm{P}$, Barbe $\mathrm{J}$ and Pagès JM: Alkylaminoquinolines inhibit the bacterial antibiotic efflux pump in multidrug-resistant clinical isolates. Biochem J 376: 801-805, 2003.

12. Phillipson JD: Phytochemistry and pharmacognosy. Phytochemistry 68: 2960-2972, 2007.

13. Gibbons S: Anti-staphylococcal plant natural products. Nat Prod Rep 21: 263-277, 2004.

14. Kalia NP, Mahajan P, Mehra R, Nargotra A, Sharma JP, Koul S and Khan IA: Capsaicin, a novel inhibitor of the NorA efflux pump, reduces the intracellular invasion of Staphylococcus aureus. J Antimicrob Chemother 67: 2401-2408, 2012.

15. He JM and Mu Q: The medicinal uses of the genus Mahonia in traditional Chinese medicine: An ethnopharmacological, phytochemical and pharmacological review. J Ethnopharmacol 175: 668-683, 2015.

16. Kaatz GW, Seo SM and Ruble CA: Mechanisms of fluoroquinolone resistance in Staphylococcus aureus. J Infectious Dis 163: 1080-1086, 1991 
17. Ross JI, Farrell AM, Eady EA, Cove JH and Cunliffe WJ: Characterisation and molecular cloning of the novel macrolide-streptogramin B resistance determinant from Staphylococcus epidermidis. J Antimicrob Chemother 24: 851-862, 1989.

18. Clinical and Laboratory Standards Institute (CLSI): Performance Standards for Antimicrobial Susceptibility Testing; Twentieth Informational Supplement. M100-S20. Vol 30. CLSI, Wayne, PA, pp54-62, 2010.

19. Hemaiswarya S, Kruthiventi AK and Doble M: Synergism between natural products and antibiotics against infectious diseases. Phytomedicine 15: 639-652, 2008.

20. Abascal K and YarnellE: Herbs and drug resistane: Part 2-Clinical implications of research on microbial resistance to antibiotics. Complementary Therapies 8: 237-241, 2002.

21. Pearson RD, Steigbigel RT and Davis HT: Method of reliable determination of minimal lethal antibiotic concentrations. Antimicrobial Agents Chemotherapy 18: 699-708, 1980.

22. Lechner D, Gibbons S and Bucar F: Plant phenolic compounds as ethidium bromide efflux inhibitors in Mycobacterium smegmatis. J Antimicrob Chemother 62: 345-348, 2008.

23. Livak KJ and Schmittgen TD: Analysis of relative gene expression data using real-time quantitative PCR and the 2(-Delta Delta $\mathrm{C}(\mathrm{T})$ ) method. Methods 25: 402-408, 2001.

24. Zhang Y: I-TASSER server for protein 3D structure prediction. BMC Bioinformatics 9: 40, 2008.

25. Roy A, Kucukural A and Zhang Y: I-TASSER: A unified platform for automated protein structure and function prediction. Nat Protoc 5: 725-738, 2010.

26. Yang J, Yan R, Roy A, Dong X, Poisson J and Yang Z: The I-TASSER Suite: Protein structure and function prediction. Nat Methods 12: 7-8, 2015.
27. Zhang J, Liang Y and Zhang Y: Atomic-level protein structure refinement using fragment guided molecular dynamics conformation sampling. Structure 19: 1784-1795, 2011.

28. Aguinagalde L, Diez-Martinez R, Yuste J, Royo I, Gil C, Lasa Í, Martín-Fontecha M, Marín-Ramos NI, Ardanuy C, Liñares J, et al: Auranofin efficacy against MDR Streptococcus pneumoniae and Staphylococcus aureus infections. J Antimicrob Chemother 70: 2608-2617, 2015.

29. Newman DJ and Cragg GM: Natural products as sources of new drugs from 1981 to 2014. J Nat Prod 79: 629-661, 2016.

30. Sibanda T and Okoh AI: The challenges of overcoming antibiotic resistance: Plant extracts as potential sources of antimicrobial and resistance modifying agents. African J Biotechnol 6: 2886-2896, 2007.

31. Sriram D, Bal TR and Yogeeswari P: Design, synthesis and biological evaluation of novel non-nucleoside HIV-1 reverse transcriptase inhibitors with broad-spectrum chemotherapeutic properties. Bioorg Med Chem 12: 5865-5873, 2004.

32. Zou D, Xie K, Wang H, Chen Y and Xie M: Inhibitory effects of biochanin A on the efflux pump of methicillin-resistant Staphylococcus aureus (MRSA). Wei Sheng Wu Xue Bao 54: 1204-1211, 2014 (In Chinese).

33. Fu Y, Wu X and Chen Z: A new approach for flexible molecular docking based on swarm intelligence. Mathematical Problems Engineering 2015: 1-10, 2015.

(i) (9) This work is licensed under a Creative Commons Attribution-NonCommercial-NoDerivatives 4.0 International (CC BY-NC-ND 4.0) License. 